\title{
Understanding the fate of nanoplastics and nanopesticides in riverine and agricultural environments
}

\author{
NiSHA Singh, EKTA TIWARI, NiTIN KHANDELWAL, \\ GOPALA KRISHNA DARBHA* \\ Department of Earth Sciences, Indian Institute of Science \\ Education and Research Kolkata, Mohanpur, 741246, \\ West Bengal, India (gkdarbha@gmail.com)
}

Nanoplastics are produced in the environment through the degradation of micro and macro sized plastics in the environment or originated as effluent from textile and paint industries. On the other hand, nanopesticides are emergent nano-agri products being utilised for agriculture for the better efficacy of active ingredients. In the current study, the assessment of bio-exposure is accomplished by understanding their stability in the riverine and agricultural environment under varying geochemical parameters.

Our results indicated that at all studied temperatures, divalent cations had a greater influence on the aggregation rate of nanoplastics as compared to monovalent cations, whereas for the same salt, drop in temperature tends to increase the stability. A rise in critical coagulation concentration (CCC) was observed by 1.6 and 2.4 times for $\mathrm{NaCl}$ and $\mathrm{CaCl}_{2}$, respectively at $15^{\circ} \mathrm{C}$ as compared to $35^{\circ} \mathrm{C}$. The clay colloids participate in hetero-aggregation with NPs under the influence of salts; this was confirmed using cryoTEM. Heavy metal such as $\mathrm{ZnCl}_{2}$ and $\mathrm{CdCl}_{2}$ had a similar interaction with PS NPs as presented by $\mathrm{CaCl}_{2}$ but showed independent behaviour in the presence of $\mathrm{HgCl}_{2}$, due to metal speciation under different redox conditions[1]. In the case of $\mathrm{CeO}_{2}$ nanopesticide, the $\mathrm{CCC}$ values obtained for $\mathrm{CeO}_{2} \mathrm{NPs}$, i.e. $26.5 \mathrm{mM}$ and $7.9 \mathrm{mM}$ for $\mathrm{NaCl}$ and $\mathrm{CaCl}_{2}$ respectively, drastically decreased to $16.2 \mathrm{mM}$ and $1.87 \mathrm{mM}$ in the presence of bentonite clay colloids. The presence of bicarbonate ions (0.1-2 mM) along with DOM (1-20 mg/ L) resulted in their stabilization and co-transport of $\mathrm{CeO}_{2}[2]$.

Reference:

[1] Nisha, Ekta, Nitin, Darbha (2019)., Environ.Sci.Nano 6, 2921-3174

[2] Ekta, Mithu, Nisha, Nitin, Fazel, Darbha (2020), RSC:

Environ. Sci. Processes Impacts : 10.1039/c9em00428a 